\title{
CONCENTRAÇÃO DE NUTRIENTES EM PLANTAS DE MILHO, ADUBADAS COM BIOFERTILIZANTES, OBTIDOS NA DIGESTÃO ANAERÓBIA DA MANIPUEIRA
}

\author{
Keles Regina Antony Inoue 1 , Cecília de Fátima Souza ${ }^{2}$, Antonio Teixeira de Matos ${ }^{3}$, Nerilson Terra Santos ${ }^{4}$, \\ Williams Pinto Marques Ferreira ${ }^{5}$
}

\begin{abstract}
RESUMO
O processamento da mandioca gera diversos tipos de resíduos, dentre os quais se destaca a manipueira, efluente altamente poluidor, por sua elevada carga orgânica e em decorrência da presença do cianeto, composto muito tóxico para plantas e animais. Uma das formas de tratamento primário dessa água residuária é a digestão anaeróbia, a qual apresenta como efluente final o biofertilizante. Objetivou-se, com este trabalho, avaliar o efeito da aplicação de diferentes doses e tipos de biofertilizantes sobre a concentração de nutrientes e a produtividade de matéria seca de plantas de milho. O experimento foi realizado no Laboratório de Digestão Anaeróbia do DEA/UFV, sendo o milho cultivado em vasos plásticos de 7,5 litros, dispostos em bancada e preenchidos com solo Cambissolo Háplico Tb distrófico latossólico. A adubação foi feita de acordo com as recomendações para a cultura. O delineamento experimental utilizado foi inteiramente casualizado, com dez tratamentos, resultantes da combinação de três biofertilizantes com três doses, além de uma testemunha. A aplicação do biofertilizante nas diferentes doses não alterou as concentrações de nitrogênio, fósforo e potássio no tecido vegetal, bem como a produção de matéria seca das plantas.
\end{abstract}

Palavras-chaves: água residuária, adubação orgânica, fertilizante.

\section{ABSTRACT \\ CONCENTRATION OF NUTRIENTS IN CORN PLANTS FERTILIZED WITH CASSAVA WASTEWATER AFTER ANAEROBIC DIGESTION}

The cassava processing generates different types of wastes, including manipueira, which is highly polluting due to its high organicloadandconcentration highly toxiccyanidecompounds. Onewaytotreatthisaffluentisthroughanaerobicdigestion, which finally yields biofertilizers as byproduct. This study was done to evaluate the effect of applying these biofertilizers at different doses on the nutrient concentration and dry matter accumulation in corn plants. The experiment was carried out in the Anaerobic Digestion Laboratory of the Agricultural Engineering Department, Federal University of Viçosa, Minas Gerais, Brazil. Corn plants were raised in 7.5 liters plastic pots filled with Cambisol Haplic Tb Distrophic Latossolic soil, in a green house. The plants were fertilized in accordance with the recommendations for the corn crop. The experiment was conducted in the completely randomized design, using three types of biofertilizers at three doses each. The non-fertilized plants served as control. The results were subjected to analysis of variance. The application of biofertilizers did not change the concentrations of nitrogen, phosphorus and potassium in the vegetative tissues, nor affect dry matter accumulation.

Keywords: Wastewater, organic fertilization, fertilizer

\section{Recebido para publicação em 03/05/2010. Aprovado em 20/01/2011.}

1- Enga Agrônoma, Doutoranda em Eng. Agrícola, Dept. de Eng. Agrícola, Universidade Federal de Viçosa, e-mail: kelesregina@hotmail.com;

2- Eng ${ }^{\mathrm{a}}$ Agrícola, D.S., Professora do Depto. de Eng. Agrícola, Universidade Federal de Viçosa, e-mail: cfsouza@ufv.br;

3- Eng ${ }^{\circ}$ Agrícola, D.S., Professor do Depto. de Eng. Agrícola, Universidade Federal de Viçosa, e-mail: atmatos@ufv.br;

4- Eng ${ }^{\circ}$ Agrônomo, D.S., Professor do Depto. De Informática, Universidade Federal de Viçosa, e-mail: nsantos@ufv.br;

5- Meteorologista, Pesquisador da Embrapa Milho e Sorgo, email: williams@cnpms.embrapa.br. 


\section{INTRODUÇÃO}

No processamento das raízes de mandioca (Manihot esculenta Crantz), são gerados diversos tipos de resíduos, como a casca, a entrecasca, o farelo e a manipueira. $\mathrm{O}$ resíduo considerado mais poluidor é a manipueira, efluente líquido, com elevada carga orgânica e concentração de cianeto.

$\mathrm{Na}$ produção do amido de mandioca, seja para a fabricação do polvilho, doce ou azedo, há geração de elevado montante de efluente líquido. A manipueira produzida na industrialização do amido pode representar cerca de $60 \%$, ou mais, do peso da matéria-prima processada (WOSIACKI \& CEREDA, 2002).

O tratamento da manipueira é, normalmente, baseado em processos físicos, químicos $\mathrm{e}$ biológicos. Os processos biológicos são alternativas para as águas residuárias de fecularia de mandioca, pois representam baixos custos de implantação e operação, quando comparados com outras tecnologias (FERNANDES JUNIOR \& TAKAHASHI, 1994).

O processo de digestão anaeróbia tem como finalidade a remoção de parte da carga orgânica, reduzindo o potencial poluidor dos resíduos, a produção e captação do metano, na forma de biogás, fonte de energia alternativa, disponibilizando, ainda, o biofertilizante (AMARAL et al., 2004).

O biofertilizante é um material orgânico que apresenta, em geral, grande poder nutricional, fornecendo elementos essenciais para $\mathrm{o}$ crescimento das plantas, como nitrogênio, fósforo, potássio. Quando aplicado ao solo, pode melhorar suas qualidades físicas, químicas e biológicas (UBALUA, 2007).

O aproveitamento de resíduos orgânicos na agricultura deve ser baseado nos teores de compostos orgânicos e nutrientes neles contidos, procurando-se maximizar os benefícios para as características químicas e físicas do solo, obtendose, com isso, maior produtividade das culturas agrícolas (ABREU JÚNIOR et al., 2005). Com esse procedimento, objetiva-se reduzir a exploração dos recursos naturais envolvidos na produção de fertilizantes e minimizar o impacto ambiental (NOGUEIRA et al., 2006).

Melo et al. (2005) avaliaram as alterações das características químicas e físicas do solo, em resposta a incubação com a manipueira, após a aplicação de doses crescentes do resíduo, e verificaram que o sódio e o magnésio trocáveis aumentaram linearmente com as doses crescentes da manipueira, nos três tipos de solos avaliados.

Pouca informação encontra-se disponível na literatura, relacionada com os efeitos, em plantas, da aplicação de biofertilizantes gerados na digestão anaeróbia de resíduos da mandioca. Assim, tornase importante a realização de pesquisas neste sentido, a fim de se definirem doses adequadas para sua utilização agrícola.

Nesse contexto, objetivou-se, com a realização deste trabalho, avaliar o efeito da aplicação de diferentes doses e tipos de biofertilizantes, sobre a produtividade de matéria seca e concentração de nutrientes, nas plantas de milho.

\section{MATERIAL E MÉTODOS}

O experimento foi realizado no Laboratório de Digestão Anaeróbia do Departamento de Engenharia Agrícola, da Universidade Federal de Viçosa/UFV. As coordenadas geográficas do Campus são $20^{\circ} 45^{\prime}$ $45^{\prime \prime} \mathrm{S}$ e $42^{\circ} 52^{\prime} 04 " \mathrm{O}$, em altitude de $649 \mathrm{~m}$. O clima predominante, de acordo com a classificação de Köppen, é Cwa (quente, temperado chuvoso, com estação seca no inverno e verão quente).

$\mathrm{O}$ experimento iniciou-se no mês de novembro de 2007 e foi finalizado em de janeiro de 2008. As unidades experimentais foram compostas por vasos plásticos com capacidade de 7,5 litros, dispostos em bancadas no Laboratório de Digestão Anaeróbia do Departamento de Engenharia Agrícola, da UFV. Os vasos foram preenchidos com 5 litros de solo, coletado na área experimental de Tratamento de Resíduos Sólidos Urbanos, do DEA. A classe textural em que o solo local enquadrou-se foi a argilosa, e a classificação, segundo critérios estabelecidos pela Sociedade Brasileira de Ciência do Solo, foi a de Cambissolo HáplicoTb distrófico latossólico, (VIEIRA, 2003).

Do material coletado, foram retiradas subamostras para análise química no Laboratório de Solos e Resíduos Sólidos do DEA/UFV. As principais características do solo, utilizado no experimento, estão apresentadas nos Quadros 1 e 2. 
Quadro 1. Características químicas iniciais do solo, utilizado no experimento

\begin{tabular}{|c|c|c|c|c|c|c|c|c|c|c|}
\hline $\mathbf{C} \mathbf{E}_{\mathrm{ES}}$ & pH & M.O. & $\mathbf{P}$ & $\mathbf{K}^{+}$ & $\mathbf{N a}^{+}$ & $\mathrm{Ca}^{+2}+\mathrm{Mg}^{+2}$ & SB & $\mathbf{A l}^{+3}$ & $\mathbf{H}+\mathbf{A l}$ & $\mathbf{V}$ \\
\hline$\mu \mathrm{S} . \mathrm{cm}^{-1}$ & $\mathrm{H}_{2} \mathrm{O}$ & dag $k^{-1}$ & \multicolumn{3}{|c|}{$\mathrm{mg} \mathrm{dm^{-3 }}$} & \multicolumn{4}{|c|}{$\mathrm{cmol}_{\mathrm{c}} \mathrm{dm}^{-3}$} & $\%$ \\
\hline 145,54 & 5,20 & 2,1 & 1,30 & 22,1 & - & 0,67 & 0,73 & 0,77 & 4,01 & 16,11 \\
\hline
\end{tabular}

Quadro 2. Características químicas do solo após ter recebido a calagem

\begin{tabular}{|c|c|c|c|c|c|c|c|c|}
\hline $\mathbf{C} \mathbf{E}_{\text {es }}$ & $\mathbf{P H}$ & $\mathbf{K}^{+}$ & $\mathbf{N a}^{+}$ & $\mathrm{Ca}^{+2}+\mathrm{Mg}^{+2}$ & SB & $\mathbf{A} \mathbf{l}^{+3}$ & $\mathbf{H}+\mathbf{A l}$ & $\mathbf{V}$ \\
\hline$\mu \mathrm{S} . \mathrm{cm}^{-1}$ & $\mathrm{H}_{2} \mathrm{O}$ & \multicolumn{2}{|c|}{$\mathbf{m g ~ d m}{ }^{-3}$} & \multicolumn{4}{|c|}{$\mathrm{cmol}_{\mathrm{c}} \mathrm{dm}^{-3}$} & $\%$ \\
\hline 648,81 & 7,20 & 17,37 & 2,33 & 2,63 & 2,68 & 0,05 & 2,51 & 51,64 \\
\hline
\end{tabular}

Quadro 3. Caracterização dos biofertilizantes, utilizados no experimento

\begin{tabular}{lccc}
\hline Parâmetro & Biofertilizante 1 & Biofertilizante 2 & Biofertilizante 3 \\
\hline Nitrogênio & $18,48 \mathrm{~g} \mathrm{~L}^{-1}$ & $17,57 \mathrm{~g} \mathrm{~L}^{-1}$ & $20,07 \mathrm{~g} \mathrm{~L}^{-1}$ \\
Fósforo & $3,48 \mathrm{~g} \mathrm{~L}^{-1}$ & $2,71 \mathrm{~g} \mathrm{~L}^{-1}$ & $2,22 \mathrm{~g} \mathrm{~L}^{-1}$ \\
Potássio & $29,06 \mathrm{~g} \mathrm{~L}^{-1}$ & $24,91 \mathrm{~g} \mathrm{~L}^{-1}$ & $19,24 \mathrm{~g} \mathrm{~L}^{-1}$ \\
Sódio & $27,69 \mathrm{~g} \mathrm{~L}^{-1}$ & $28,61 \mathrm{~g} \mathrm{~L}^{-1}$ & $33,98 \mathrm{~g} \mathrm{~L}^{-1}$ \\
$\mathrm{pH}$ & 5,04 & 5,20 & 5,01 \\
$\mathrm{CE}$ & $6,93 \mathrm{mS} \mathrm{cm}$ & $8,24 \mathrm{mS} \mathrm{cm}$ & $11,53 \mathrm{mS} \mathrm{cm}^{-1}$ \\
Sólidos totais (ST) & $2,1 \mathrm{dag} \mathrm{kg}^{-1}$ & $2,82 \mathrm{dag} \mathrm{kg}^{-1}$ & $5,4 \mathrm{dag} \mathrm{kg}^{-1}$ \\
COT & $1,15 \mathrm{dag} \mathrm{kg}^{-1}$ & $1,63 \mathrm{dag} \mathrm{kg}^{-1}$ & $3,05 \mathrm{dag} \mathrm{kg}^{-1}$ \\
\hline
\end{tabular}

Em cada vaso, foram semeadas três sementes de milho da variedade UFV DKB 333B. O desbaste foi feito após a emergência das plantas, deixando-se somente uma planta por vaso.

As doses aplicadas dos biofertilizantes foram baseadas no fornecimento de sódio ao solo, já que era o elemento que se apresentava em maior concentração relativa, como pode ser observado no Quadro 3.

Os biofertilizantes utilizados foram obtidos a partir de três diferentes concentrações de sólidos totais (ST) do substrato (manipueira e casca de mandioca), adicionado aos biodigestores.

O biofertilizante 1 foi produzido a partir da concentração de 4,5 dag $\mathrm{L}^{-1}$ de ST; o biofertilizante 2, a partir da concentração 6 dag $\mathrm{L}^{-1}$ de ST e o biofertilizante 3, a partir da concentração 8 dag $\mathrm{L}^{-1}$ de ST. As combinações foram as seguintes:

D 0 - testemunha - sem biofertilizante; B1 D1 - biofertilizante 1 , com dose de $100 \mathrm{~kg} \mathrm{ha}^{-1} \mathrm{ano}^{-1}$ de sódio; B1 D2 - biofertilizante 1, com dose de $200 \mathrm{~kg} \mathrm{ha}^{-1}$ ano $^{-1}$ de sódio; B1 D3 - biofertilizante 1, com dose de $300 \mathrm{~kg} \mathrm{ha}^{-1}$ ano $^{-1}$ de sódio; B2 D1 - biofertilizante 2, com dose de $100 \mathrm{~kg} \mathrm{ha}^{-1} \mathrm{ano}^{-1}$ de sódio; B2 D2 - biofertilizante 2, com dose de $200 \mathrm{~kg} \mathrm{ha}^{-1}$ ano $^{-1}$ de sódio; B2 D3 - biofertilizante 2, com dose de $300 \mathrm{~kg} \mathrm{ha}^{-1}$ ano $^{-1}$ de sódio; B3 D1 biofertilizante 3, com dose de $100 \mathrm{~kg} \mathrm{ha}^{-1} \mathrm{ano}^{-1}$ de sódio; B3 D2 - biofertilizante 3, com dose de 200 $\mathrm{kg} \mathrm{ha}^{-1}$ ano $^{-1}$ de sódio; B3 D3 - biofertilizante 3, com dose de $300 \mathrm{~kg} \mathrm{ha}^{-1} \mathrm{ano}^{-1}$ de sódio.

A aplicação do biofertilizante foi realizada somente após a emergência das plantas, em uma única dosagem, quando elas haviam atingido, aproximadamente, $10 \mathrm{~cm}$ de altura. A colheita das plantas e do solo para análise foi realizada 44 dias após a aplicação do biofertilizante.

Foram avaliadas as seguintes variáveis na parte aérea das plantas: massa seca e concentração de nitrogênio, fósforo e potássio. Para a quantificação 
da massa seca, as plantas coletadas foram pesadas em balança digital. Posteriormente, foram levadas para secagem em estufa com circulação forçada de ar, sob temperatura de $65^{\circ} \mathrm{C}$, por um período de 72 horas. Em seguida, as amostras foram novamente pesadas em balança digital. As amostras secas em estufa foram moídas em moinho tipo "Wiley", para posterior análise. No material, foram quantificadas as concentrações de nitrogênio, fósforo e potássio.

A análise do nitrogênio foi realizada pelo método Kjeldahl, em que a amostra é submetida a uma digestão ácida, convertendo o nitrogênio em amônio e, depois, em amônia, com posterior destilação e titulação da amônia. O fósforo disponível foi analisado por método colorimétrico e, o potássio, por fotometria de chama (EMBRAPA, 1999).

O delineamento experimental utilizado foi o Delineamento Inteiramente Casualizado (DIC), com dez tratamentos, resultantes da combinação de três biofertilizantes e três doses, além de uma testemunha. Cada um dos tratamentos foi destinado a dois vasos, que correspondeu ao número de repetições. Os dados obtidos foram submetidos à análise de variância, utilizando-se o programa SAS.

\section{RESULTADOS E DISCUSSÃO}

No Quadro 4, estão apresentados os resultados da análise de variância para os elementos avaliados na planta. Com base nos resultados apresentados, podese verificar que não houve diferença significativa para as variáveis avaliadas na planta, a $5 \%$, pelo teste $\mathrm{F}$.

Avaliando-se os resultados apresentados no Quadro 4, verifica-se que não houve diferença significativa entre as médias de tratamentos para matéria seca, a $5 \%$ de probabilidade, pelo teste $\mathrm{F}$, ou seja, a aplicação do biofertilizante não influenciou na produtividade da matéria seca das plantas de milho, até os 55 dias após sua emergência, quando foi realizado o corte de sua parte aérea.

Na Figura 1, estão apresentados os valores médios de conteúdo de matéria seca nas plantas testemunhas e nas submetidas aos demais tratamentos.

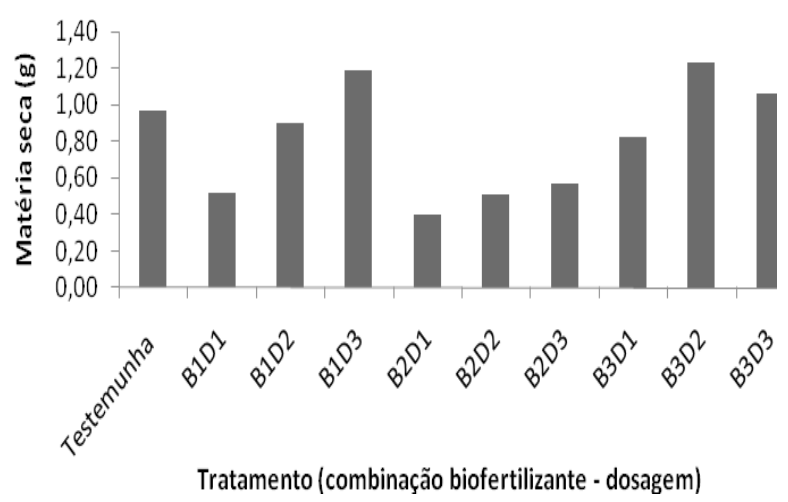

Figura 1. Valores médios de matéria seca $(\mathrm{g})$ na planta testemunha e nas demais plantas, submetidas à aplicação de diferentes doses de biofertilizante.

Observa-se, na Figura 1, que os valores obtidos, de massa seca, nos tratamentos avaliados, apresentaram teores bem variados, fato este comprovado pelo alto valor do coeficiente de variação, provavelmente em função do período de germinação e desenvolvimento diferenciado das plantas, apesar de elas terem sido semeadas com as mesmas condições de temperatura e umidade do solo.

Roel et al. (2007) avaliaram a utilização de fertilizantes orgânicos na produção de alface e observaram que houve diferença significativa na massa seca das plantas, entre a testemunha e os tratamentos avaliados com composto orgânico à base de palhada de soja, feijão e milho, acrescidos de esterco de galinha.

Quadro 4. Fontes de variação, quadrados médios e respectivas significâncias para os componentes avaliados na planta, matéria seca $(\mathrm{MS})$, nitrogênio $(\mathrm{N})$, fósforo $(\mathrm{P})$ e potássio $(\mathrm{k})$

\begin{tabular}{lllccc}
\hline \multirow{2}{*}{$\mathbf{F V}$} & & \multicolumn{4}{c}{ QM } \\
\cline { 3 - 6 } \multicolumn{1}{c}{ Gl } & MS & N & P & K \\
\hline Tratamentos & 9 & $0,21^{\text {ns }}$ & $2040330,20^{\text {ns }}$ & $935544,98^{\text {ns }}$ & $36723185,9^{\text {ns }}$ \\
Resíduo & 8 & 0,38 & 3909987,69 & 1018756,74 & 61639288,5 \\
$\widehat{m}$ & - & 0,96 & 16010,71 & 2735,36 & 31575,44 \\
CV $(\%)$ & - & 64,30 & 12,35 & 36,90 & 24,86 \\
\hline
\end{tabular}

${ }^{\text {ns }}$ não significativo a $5 \%$ de probabilidade pelo teste $\mathrm{F}$. 
Silva et al. (2006) realizaram estudo para avaliar a produtividade de matéria seca e verde na Brachiaria brizantha CV. Marandu, após a aplicação de biofertilizante bovino, obtido por digestão aneróbia, e observaram que o aumento das doses do biofertilizante não promoveu aumento significativo na produção de massa seca e massa fresca na planta.

Os teores médios de nitrogênio, na parte áerea das plantas de milho, cultivadas em solo testemunha e em solo sob aplicação de diferentes doses e tipos de biofertilizantes, estão apresentados na Figura 2.

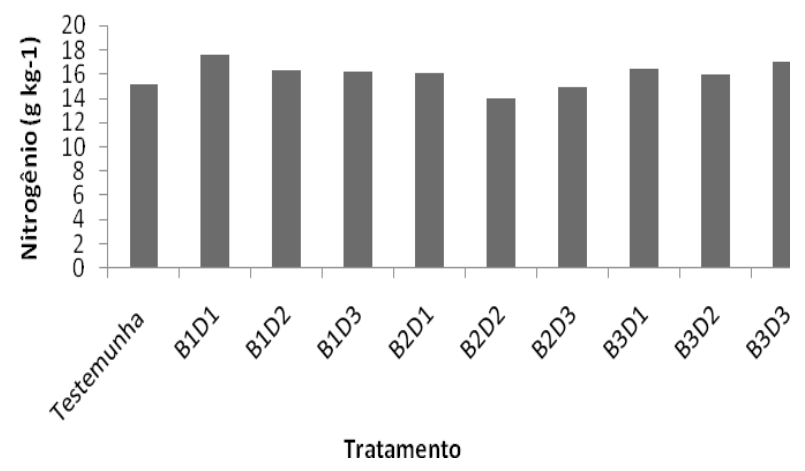

Figura 2. Concentrações médias de nitrogênio na planta testemunha e nas demais plantas, submetidas à aplicação de diferentes doses de biofertilizante.

Avaliando-se os resultados apresentados no Quadro 4, verifica-se que não houve diferença significativa entre as médias dos tratamentos, para a concentração de nitrogênio total na parte aérea das plantas,a $5 \%$ de probabilidade, pelo teste $\mathrm{F}$, evidenciando-se que a aplicação do biofertilizante não alterou as concentrações de nitrogênio na planta.

O acúmulo de nitrogênio em plantas cultivadas em solos tratados com lodo de esgoto foi avaliado por Biondi \& Nascimento (2005). Esses autores perceberam que as doses de lodo elevaram os teores de nitrogênio na matéria seca, nas duas culturas avaliadas (feijão e milho), proporcionalmente ao aumento das doses.

Fia et al. (2006) avaliaram a produtividade e a concentração de nutrientes em milho, adubado com crescentes doses de lodo de esgoto caleado, e verificaram que as concentrações de nitrogênio foram crescentes, com o aumento na dose do resíduo aplicado ao solo. Os mesmos autores afirmaram que, apesar do aumento na concentração de nitrogênio na planta, nenhum tratamento apresentou a concentração considerada adequada para a cultura do milho, aos 60 dias de cultivo, que, segundo Jones Junior et al. (1991), está na faixa de $3,0-3,5 \mathrm{dag} \mathrm{kg}^{-1}$. De acordo com as informações apresentadas por estes autores, e observando-se as concentrações de nitrogênio apresentadas na Figura 2 , pode-se verificar que nenhum dos tratamentos avaliados apresentou a concentração de nitrogênio, considerada adequada para a cultura do milho, na fase em que a concentração deste nutriente foi avaliada nas plantas.

De acordo com as informações apresentadas no Quadro 4, verifica-se que não houve diferença significativa entre as médias de tratamentos para a concentração de fósforo total na parte aérea das plantas, a $5 \%$ de probabilidade, pelo teste $\mathrm{F}$, evidenciando-se, assim, que a aplicação do biofertilizante não influenciou na concentração de fósforo total na planta do milho.

$\mathrm{Na}$ Figura 3, estão apresentadas as concentrações de fósforo total na parte aérea das plantas testemunhas e naquelas submetidas aos demais tratamentos.

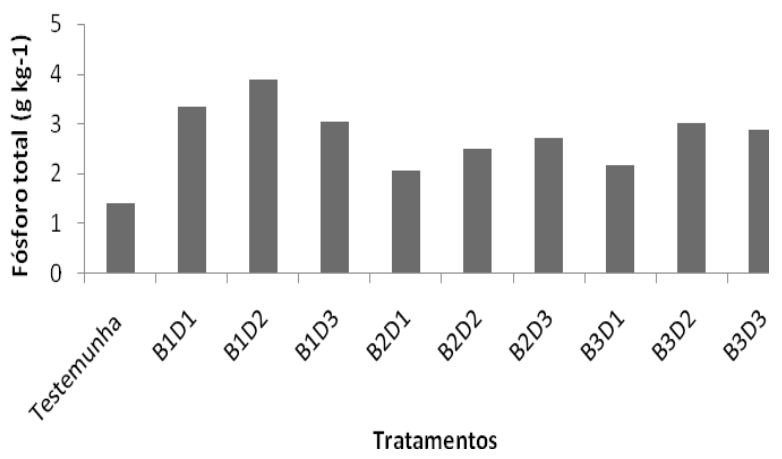

Figura 3. Concentrações médias de fósforo total na planta testemunha e nas demais plantas, submetidas à aplicação de diferentes doses de biofertilizante.

Na Figura 3, pode-se observar que os valores absolutos da concentração de fósforo tenderam a ser superiores, em todos os tratamentos que receberam biofertilizante, quando comparados com os obtidos no tratamento testemunha. Esse valor é ainda mais elevado nos tratamentos que receberam o biofertilizante 1, provavelmente em função da 
presença desse elemento em maior concentração nesse biofertilizante.

Gomes et al. (2007) realizaram estudo para avaliar a produtividade e a composição mineral das plantas de milho, em solo adubado com lodo de esgoto, e concluíram que o teor de fósforo não sofreu influência dos tratamentos com lodo e que as concentrações de fósforo estiveram abaixo das adequadas para a cultura (EMBRAPA, 1999). Os autores relataram, ainda, que não verificaram sintomas de deficiência deste elemento em nenhum dos tratamentos.

Moura et al. (2007) avaliaram a eficiência de biofertilizantes de rocha fosfatada e potássica, no cultivo do melão, no Vale do São Francisco, e verificaram que o biofertilizante fosfatado (aplicado na maior dose) e a mistura de rochas (fosfatada e potássica) proporcionaram os melhores resultados na acumulação de fósforo total na parte aérea do meloeiro.

Conforme informação apresentada no Quadro 3, verifica-se que não houve diferença significativa entre as concentrações médias de potássio total, na parte aérea das plantas, a $5 \%$ de probabilidade, pelo teste $\mathrm{F}$, ou seja, a aplicação do biofertilizante não influenciou na concentração desse elemento na planta. Na Figura 4 , estão apresentadas as concentrações de potássio total $\left(\mathrm{g} \mathrm{kg}^{-1}\right)$, na parte aérea das plantas testemunhas e naquelas submetidas aos demais tratamentos.

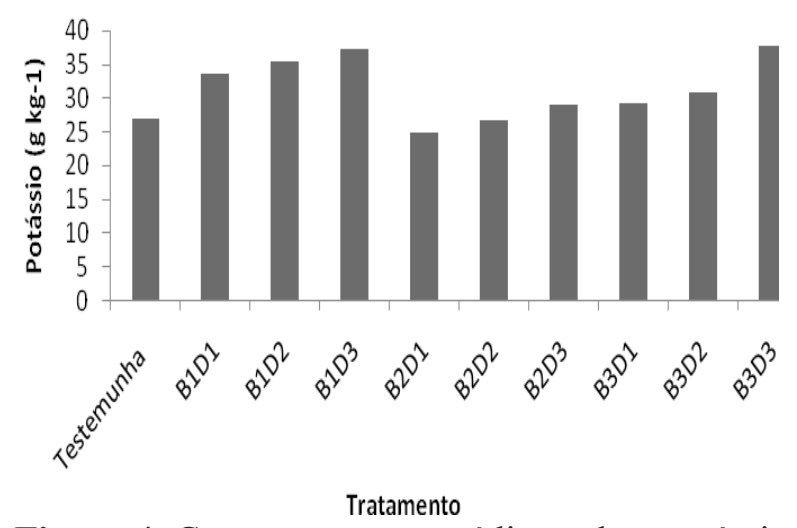

Figura 4. Concentrações médias de potássio total $\left(\mathrm{g} \mathrm{kg}^{-1}\right)$ na parte aérea da planta testemunha e nas demais plantas, submetidas à aplicação de diferentes doses de biofertilizante.

As concentrações médias de potássio aumentaram consideravelmente, após a aplicação do biofertilizante, nas diferentes doses, com exceção das obtidas nos tratamentos B2D1 e B2D2, que apresentaram valores absolutos similares ao obtido na testemunha, como pode ser observado na Figura 20. No entanto, mesmo tendo apresentado concentrações de potássio total mais elevadas, não houve diferença entre a que foi obtida na testemunha, em relação aos demais tratamentos.

Gomes et al. (2007) realizaram estudo para avaliar a produtividade e a composição mineral das plantas de milho, em solo adubado com lodo de esgoto $\left(0,0 ; 7,7 ; 15,4 ; 29,7 ; 45,1\right.$ e $60,5 \mathrm{t} \mathrm{ha}^{-1}$, em base seca) e observaram que a concentração de potássio permaneceu sempre próxima dos teores considerados adequados (17 a $\left.35 \mathrm{~g} \mathrm{~kg}^{-1}\right)$ para a cultura do milho, conforme EMBRAPA (1999), em todos os tratamentos avaliados.

Duenhas et al. (2004) estudaram os teores de macronutrientes em plantas de melão, cultivado em sistema orgânico, fertirrigado com substâncias húmicas, e observaram que a maior dose de potássio foi verificada nas plantas que receberam fertirrigação com o biofertilizantes (maior dose de potássio no início do ciclo), aliada à presença de esterco.

\section{CONCLUSÕES}

- Os biofertilizantes produzidos apresentaram concentrações elevadas de nitrogênio, fósforo e potássio, caracterizando-os como fertilizantes orgânicos, entretanto, apresentaram concentrações preocupantes de sódio, o que requer cuidados na definição das doses de aplicação no solo;

- Não se verificaram diferenças na produtividade de matéria seca e nas concentrações de N, P e K, no tecido das plantas que receberam diferentes tipos e doses de biofertilizante; e

- A viabilidade da utilização do biofertilizante vai depender do tipo de cultura, bem como das características do solo que vai receber esse efluente, tendo como base o atendimento às necessidades nutricionais das culturas, evitando-se, também, exceder no solo a concentração dos elementos presentes no biofertilizante. 


\section{REFERÊNCIAS BIBLIOGRÁFICAS}

ABREU JUNIOR, C.H.; BOARETTO, A.E.; MURAOKA, T. \& KIEHL, J.C. Uso agrícola de resíduos orgânicos. In: Propriedades químicas do solo e produção vegetal. TORRADO, P.V.; ALLEONI, L.R.F.; COOPER, M.; SILVA, A.P. \& CARDOSO, E.J., eds. Tópicos em ciência do solo. Viçosa, MG, Sociedade Brasileira de Ciência do Solo, 2005. v.4. p.391-479.

AMARAL, C.M.C.; AMARAL, L.A.; LUCAS JÚNIOR, J.; NASCIMENTO, A.A.; FERREIRA, D.S.; MACHADO, M.R.F. Biodigestão anaeróbia de dejetos de bovinos leiteiros submetidos a diferentes tempos de retenção hidráulica. Ciência Rural, Santa Maria, v.34, n.6, nov-dez, 2004.

BIONDI, C.M.; NASCIMENTO, C.W.A. Acúmulo de nitrogênio e produção de matéria seca de plantas em solos tratados com lodo de esgoto. Caatinga, Mossoró-RN, v.18, n.2, p.123-128, abr./jun. 2005.

DUENHAS, L.H.; PINTO, J.M.; GOMES, T.C.A. Teores de macronutrientes em plantas de melão cultivado em sistema orgânico fertirrigado com substâncias húmicas. In: $44^{\circ}$ Congresso Brasileiro de Olericultura, 2004, Campo Grande. 44 CBO. Resumos... Campo Grande: Embrapa, 2004.

EMBRAPA - Empresa Brasileira de Pesquisa Agropecuária. Manual de análises químicas de solos, plantas e fertilizantes. Brasília: EMBRAPA, 1999. 370p.

FIA, R.; MATOS, A.T.; AGUIRRE, C.I. Produtividade e concentração de nutrientes e metais pesados em milho adubado com doses crescentes de lodo de esgoto caleado. Engenharia na Agricultura, Viçosa, MG, v.14, n.1, p.39-50, Jan/Mar, 2006.

FERNANDES JUNIOR, A.; TAKAHASHI, M. Tratamento da manipueira por processos biológicos - aeróbio e anaeróbio. In: CEREDA et al., Industrialização da mandioca. São Paulo: Ed. Paulicéia, 1994. 174p.

GOMES, S.B. V.; NASCIMENTO, W.A. BIONDI, C.M. Produtividade e composição mineral de plantas de milho em solo adubado com lodo de esgoto. R. Bras. Eng. Agríc. Ambiental, Campina Grande, v.11, n.5, p.459465, 2007.

JONES JR, J.B.; WOLF, B.; MILLS, H.A. Plant analysis handbook - a pratical sampling, preparation, analysis, and interpretation guide. Georgia, USA: Micro-Macro Plublishing, Inc., 1991. 213p.

MELO, R.F.; FERREIRA, P.A.; RUIZ, H.A.; MATOS, A.T.; OLIVEIRA, L.B. Alterações físicas e químicas em três solos tratados com água residuária de mandioca. Irriga, Botucatu, v.10, n.4, p.383-392, novembro-dezembro, 2005.

MOURA, P. M.; STAMFORD, N. P.; DUENHAS, L. H.; SANTOS, C. E. R. S.; NUNES, G. H. S. Eficiência de biofertilizantes de rochas com Acidithiobacillus em melão, no Vale do São Francisco. Rev. Bras. Ciênc. Agrár. Recife, v.2, n.1, p.1-7, 2007.

NOGUEIRA, T.A.R.; SAMPAIO, R.A.; FERREIRA, C.S.; FONSECA, I.M. Produtividade de milho e de feijão consorciados adubados com diferentes formas de lodo de esgoto. Revista de Biologia e Ciências da Terra, v.6, n.1, $1^{\circ}$ Semestre, 2006.

ROEL, A.R.; LEONEL, L.A.K. ; FAVARO, S. P.; ZATARIM, M.; MOMESSO, C. M. V.; SOARES, M. V. Avaliação de fertilizantes orgânicos na produção de alface em Campo Grande, MS. Scientia Agraria, Curitiba, v.8, n.3, p.325-329, 2007 (Nota Científica).

SILVA, A.A.; XAVIER, C.A.N.; MORALES, M.M.; LUCAS JUNIOR, J. Produtividade de matéria seca e matéria verde da Brachiaria brizantha CV. Marandu após aplicação de biofertilizante bovino obtido por biodigestão anaeróbia com e sem uso de caldo de cana como 
aditivo. In: RAIB- Reunião Anual do Instituto Biológico, 19, 2006. São Paulo. Resumos... São Paulo: 2006.

UBALUA, A.O. Cassava wastes: treatment options and value addition alternatives. African Journal of Biotechnology, n.10, p. 2065-2073, 2007.

VIEIRA, E. O. Índice de lixiviação e modelagem do transporte de pesticidas no solo. Viçosa MG: UFV, 2003. 184f. Tese (Doutorado em Solos e Nutrição de Plantas) - Universidade Federal de Viçosa, Viçosa. 2003.

WOSIACKI, G.; CEREDA, M.P. Valorização dos resíduos do processamento da mandioca. Ciências Exatas e da Terra, C. Agrárias e Engenharias, v.8, n.1; p.27-43, 2002. 